\title{
APROVEITAMENTO DO RESÍDUO DE TANQUE DE PISCICULTURA NA PRODUÇÃO DE MUDAS DE MAMOEIRO EM RORAINÓPOLIS
}

\section{USE OF PISCICULTURE TANK WASTE IN THE PRODUCTION OF PAPAYA MUDS IN RORAINOPOLIS}

\author{
Daniely Karina de Oliveira Franciosi Rosa ${ }^{1}$ \\ Danieli Lazarini de Barros ${ }^{2}$ \\ Francisco Péricles Galúcio Aires ${ }^{3}$ \\ Plínio Henrique Oliveira Gomide ${ }^{3}$
}

RESUMO: No Estado de Roraima, a fruticultura é limitada de informações consistentes, referentes ao potencial produtivo de mudas para exploração a campo. $\mathrm{O}$ objetivo do estudo foi avaliar o crescimento inicial de mudas e produção de biomassa de mamoeiro, produzidas a partir de resíduo proveniente de tanques de piscicultura. $\mathrm{O}$ experimento foi realizado em casa de vegetação utilizando como materiais para a composição dos substratos, solo de barranco (SB), resíduo proveniente de tanques de piscicultura (RP), substrato comercial - Vivatto (VT) e casca de arroz carbonizada (CAC). Os tratamentos (substratos) foram: $\mathrm{T} 1=$ testemunha constituída pelo substrato comercial Vivatto, T2: $25 \% \mathrm{RP}+75 \% \mathrm{SB}, \mathrm{T} 3: 50 \% \mathrm{RP}+50 \% \mathrm{SB}, \mathrm{T} 4: 25 \% \mathrm{SB}+75 \%$ RP e T5: $100 \%$ RP, a todos os tratamentos foi adicionado CAC como condicionador dos substrato. Foi utilizado o delineamento inteiramente casualizado com 5 tratamentos e 5 repetições, totalizando 25 parcelas experimentais. As variáveis analisadas foram: número de folhas/planta, diâmetro do coleto $(\mathrm{mm})$ com uso de paquímetro digital da marca Insize, altura da muda $(\mathrm{cm})$ com uso de uma régua graduada em $\mathrm{cm}$ medindo a partir do coleto da muda até a gema apical, matéria fresca e seca da parte aérea e matéria seca e fresca de raiz após 60 dias do transplantio das plântulas. Observou-se que o tratamento T1 apresentou o maior número médio de folhas, maior produção de massa fresca e massa seca da parte aérea, e maior acúmulo de massa fresca e seca da raiz $(\mathrm{P}<0,05)$. Os piores resultados ocorreram para o tratamento com $25 \%$ de resíduo proveniente de tanques de piscicultura (T2), o qual apresentou a menor uniformidade das variáveis estudadas. A altura do caule das plantas de mamoeiro foi superior para os tratamentos T1 e para o T5 que incluiu resíduo de piscicultura. Desta forma, o substrato

\footnotetext{
${ }^{1}$ Acadêmica do Curso de Agronomia da Universidade Estadual de Roraima - UERR. (dany_franciosi@hotmail.com)

${ }^{2}$ Professora do Instituto Federal de Roraima - IFRR.

${ }^{3}$ Professores do Curso de Agronomia da Universidade Estadual de Roraima - UERR.
} 
comercial apresentou respostas superiores as variáveis analisadas para a produção de mudas de mamoeiro bem como o resíduo de piscicultura, tornando-o uma boa alternativa para o aproveitamento deste resíduo para produção de mudas.

Palavras-chave: Carica papaya. Biomassa. Substratos alternativos. Alternativa sustentável.

ABSTRACT: In the State of Roraima, fruit growing is limited with consistent information regarding the productive potential of seedlings for field exploration. The objective of the study was to evaluate the initial growth of seedlings and biomass production of papaya, produced from the residue from fish farming tanks. The experiment was carried out in a greenhouse using as materials for the substrate composition, ravine soil (SB), residue from fish farms (PR), commercial substrate Vivatto (VT) and charcoal rice husk (CAC). The treatments (substrates) were: $\mathrm{T} 1=$ control consisting of the commercial substrate Vivatto, T2: $25 \% \mathrm{RP}+75 \% \mathrm{SB}, \mathrm{T} 3$ : $50 \% \mathrm{RP}+50 \% \mathrm{SB}, \mathrm{T} 4: 25 \% \mathrm{SB}+75 \% \mathrm{RP}$ and $\mathrm{T} 5: \mathrm{RP}$, all treatments were added CAC as substrate conditioner. A completely randomized design with 5 treatments and 5 replicates was used, totaling 25 experimental plots. The variables analyzed were: number of leaves / plant, collection diameter $(\mathrm{mm})$ with the use of a digital caliper of the Insize brand, height of the seedling $(\mathrm{cm})$ with the use of a ruler graduated in $\mathrm{cm}$ measuring from the collection of the seedling to the yolk apical, fresh and dry matter of aerial part and fresh dry matter of root after 60 days of the transplantio of the seedlings. It was observed that the T1 treatment had the highest average number of leaves, higher fresh mass production and dry shoot mass, and greater accumulation of fresh and dry root mass $(\mathrm{P}<0.05)$. The worst results occurred for the treatment with $25 \%$ of the residue from fish farms (T2), which presented the lowest uniformity of the studied variables. The stem height of the papaya plants was higher for the T1 treatments and for the T5, which included pisciculture residue. In this way, the commercial substrate showed higher responses to the analyzed variables for the production of papaya seedlings as well as the fishery residue, making it a good alternative for the use of this residue for seedling production.

Key words: Carica papaya. Biomass. Alternative substrates. Sustainable alternative.

\section{INTRODUÇÃOO}

A busca diária do homem pela sobrevivência gera resíduos diversos. Os resíduos provenientes das indústrias do setor madeireiro, alimentício ou agropecuários têm sido um dos grandes passivos ambientais. Grande parte do material proveniente dessas atividades é descartado em locais inadequados o que não gera apenas poluição visual, parte desses materiais apresentam características químicas que quando em contato direto com o meio podem acarretar danos ao ecossistema. 
Em se tratando das atividades agropecuárias, as atividades realizadas em viveiros de peixe geram resíduos, e todo o material orgânico proveniente da adição de fertilizantes, excreção dos peixes e restos de ração não consumidos pelos peixes, encontram-se dissolvidos na água de forma solúvel ou acumulados no sedimento dos tanques de forma sólida. Em tanques com sistemas de circulação intermitente, estes produtos encontram-se no efluente, que geralmente é descartado em algum corpo receptor sem que haja nenhum tratamento. (HUSSAR et al., 2002, CHAVES; SILVA, 2006).

A constante busca em minimizar os danos causados ao meio ambiente através do descarte desses resíduos faz com que se busque alternativas viáveis, e o seu reuso na agricultura tem sido uma alternativa positiva agregando características químicas, físicas e econômicas para a formação de substratos utilizados para produção de mudas, conforme afirmam Chaves e Silva (2006), uma maneira de minimizar os impactos causados pelos efluentes provenientes de tanques de piscicultura, é fazer o reuso destes na agricultura ou fazer aplicação de métodos de tratamento.

A agricultura está em constante expansão, e a procura por substratos alternativos visando mudas de qualidade e economia durante o processo de produção de mudas é grande.

A produção de mudas constitui uma das etapas de maior importância de um sistema produtivo. Smiderle \& Minami (2001), ressaltam que para a produção de mudas frutíferas um bom substrato deve proporcionar a planta uma boa capacidade de retenção de água e quando esta estiver em excesso, o mesmo deve manter-se poroso para que haja o adequado fornecimento de oxigênio que é indispensável no processo de produção de mudas e fotossíntese, além de fornecer todos os nutrientes necessários ao desenvolvimento das plantas. Estes autores afirmam que o substrato exerce grande influencia sobre a formação de mudas, interferindo diretamente nas fases iniciais de desenvolvimento da planta.

O Brasil possui grande potencial para a produção de frutíferas sendo o mamão uma cultura de grande importância socioeconômica para o país. O mamoeiro pertence à família Caricaceae, é uma frutífera originária da América Tropical (KOEHLER, 2004), desenvolve-se bem em climas tropicais e subtropicais e seu fruto tem grande aceitação para consumo in natura e industrializado. 
Apesar da grande importância que a cultura do mamoeiro exerce sobre a fruticultura do país, poucas pesquisas são relacionadas a essa frutífera principalmente em se tratando da formação de mudas (MENDONÇA et al., 2003). Mesmo com informações de que grande parte dos resíduos advindos da atividade piscícola acumulase nos sedimentos dos tanques e estes apresentam altas concentrações de nutrientes, ainda são escassos ou até mesmo inexistentes estudos referentes à utilização deste subproduto no estado de Roraima, sendo este estudo pioneiro no município de Rorainópolis utilizando esses resíduos para a produção de mudas de mamoeiro.

Deste modo, o objetivo deste trabalho foi avaliar o crescimento inicial de mudas e seu vigor sob o efeito de diferentes doses de resíduos de tanque de piscicultura na formação de mudas de mamoeiro.

\section{MATERIAL E MÉTODOS}

O experimento foi realizado na Universidade Estadual de Roraima, Rorainópolis, RR no período de 17 de maio de 2018 a 23 de julho de 2018. O município de Rorainópolis está localizado na região sul do Estado de Roraima, apresenta vegetação composta por Floresta Ombrófila, clima tropical quente, com temperatura média anual de $26^{\circ} \mathrm{C}$ e precipitação pluviométrica de $1.750 \mathrm{~mm}$ na mesorregião Sul, microrregião Sudeste, situado nas coordenadas geográficas $60^{\circ} 25^{\prime} 47^{\prime \prime}$ de longitude Oeste e $00^{\circ} 56^{\prime} 46^{\prime \prime}$ de latitude Norte, predominando o clima quente, com chuvas de verão e outono (AWI) (SEPLAN, 2014).

O experimento foi implantado em casa de vegetação, sobre bancada com $1 \mathrm{~m}$ de altura dimensões de $2 \mathrm{~m}$ x $0,5 \mathrm{~m}$, sob sombrite $50 \%$ e lona transparente de 100 micras de espessura. Foram utilizados três tipos de materiais na composição dos substratos para a produção de mudas de mamão formosa, sendo: solo de barranco (SB), resíduo proveniente de tanques de piscicultura (RP) e como testemunha um substrato comercial (Vivatto). Os tratamentos utilizados foram: T1: 100\% de substrato comercial Vivatto (testemunha), T2: $25 \% \mathrm{RP}+75 \% \mathrm{SB}, \mathrm{T3}: 50 \% \mathrm{RP}+50 \% \mathrm{SB}, \mathbf{T} 4: 25 \% \mathrm{SB}+75 \% \mathrm{RP}$ e T5: $100 \%$ RP. A todos os tratamentos foram adicionados $1 \mathrm{~kg}$ de casca de arroz carbonizada (CAC), como forma de manter a porosidade facilitando assim a drenagem da água e desenvolvimento do sistema radicular das plântulas. O delineamento 
experimental foi inteiramente casualizado (DIC), com 5 tratamentos e 5 repetições cada, totalizando 25 parcelas experimentais.

As amostras de resíduos de fundo de tanque escavado foram coletadas no mês de março de 2018, na vicinal 02 no município de Rorainópolis, RR, 15 dias após a despesca do tanque, o mesmo é utilizado a cerca de três anos com o cultivo de tambaqui e tilápia, seguindo os preceitos de utilização de calagem, cal e estercos para manter um bom pH e oxigenação da água, e a alimentação dos peixes se dá pelo uso de rações de diferentes composições de acordo com o estágio de crescimento dos peixes.

Os substratos foram caracterizados quanto à sua composição química. A composição química dos substratos a base de resíduo de piscicultura encontram-se descritos na tabela 1, e a composição química do substrato comercial encontra-se descrita a seguir:

O substrato comercial (Vivatto) apresentou as seguintes características químicas: pH: 5,6 g/kg; N: 7,00 g/kg; P: 4,30 g/kg; K:7,32 g/kg; Ca: 5,29 g/kg; Mg: 8,01 g/kg; S: 3,85 g/kg; B: 23,70 mg/kg; Cu: 42,10 mg/kg; Fe: 10971,47 mg/kg; Mn: $470 \mathrm{mg} / \mathrm{kg}$; Zn: $308 \mathrm{mg} / \mathrm{kg}$.

Tabela 1 - Composição química dos substratos a base de resíduo de piscicultura utilizado na produção de mudas de mamoeiro em Rorainópolis.

\begin{tabular}{|c|c|c|c|c|c|c|c|c|c|c|c|c|c|}
\hline Tratamento & $\mathbf{p H}$ & $\mathrm{Ca}^{2+}$ & $\mathrm{Mg}^{2+}$ & $\mathbf{K}^{+}$ & $\mathbf{A l}^{3+}$ & $\mathbf{H}+\mathbf{A l}$ & $\mathbf{P}$ & SB & $\mathbf{T}$ & $\mathbf{t}$ & $\mathbf{V}$ & $\mathbf{m}$ & MOS \\
\hline & $\mathrm{H}_{2} \mathrm{O}$ & & ........c & holcdr & $\mathrm{A}^{3}$. & & $\mathrm{mg}$ & \multicolumn{3}{|c|}{-cmolcdm ${ }^{3}-$} & \multicolumn{2}{|c|}{$\ldots \% \ldots$} & $\mathrm{g} \mathrm{kg}^{-}$ \\
\hline $\mathrm{T} 2$ & 5,7 & 0,67 & 0,47 & 1,51 & 0,03 & 1,29 & 27,77 & 2,65 & 3,94 & 2,68 & 67 & 1 & 10,19 \\
\hline $\mathrm{T} 3$ & 5,7 & 1,05 & 0,68 & 1,70 & 0,02 & 1,62 & 27,73 & 3,43 & 5,05 & 3,45 & 68 & 1 & 12,05 \\
\hline $\mathrm{T} 4$ & 6,1 & 1,80 & 0,80 & 1,52 & 0,01 & 1,82 & 30,10 & 4,12 & 5,94 & 4,13 & 69 & 0 & 14,84 \\
\hline $\mathrm{T} 5$ & 6,1 & 1,90 & 0,85 & 1,73 & 0,01 & 2,03 & 37,54 & 4,48 & 6,51 & 4,49 & 69 & 0 & 19,72 \\
\hline $\begin{array}{l}\mathrm{Ca}^{2+}: \text { Cálcio tr } \\
\text { potencial. Sb: } \\
\text { alumínio. V: }\end{array}$ & na & $\mathrm{g}^{2+}$ & gne & 8 & $\begin{array}{l}\text { el. } \\
\text { va. }\end{array}$ & $\begin{array}{l}{ }^{+}: \mathrm{A} \\
\mathrm{CT}\end{array}$ & nínio & & $\mathrm{H}-$ & $\mathrm{ac}$ & & & 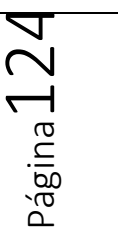 \\
\hline
\end{tabular}
constituída pelo substrato Vivatto, T2: $25 \% \mathrm{RP}+75 \% \mathrm{SB}, \mathrm{T} 3: 50 \% \mathrm{RP}+50 \% \mathrm{SB}, \mathrm{T} 4$ : $25 \% \mathrm{SB}+75 \% \mathrm{RP}$ e T5: $100 \% \mathrm{RP}$ 
As sementes de mamão formosa utilizadas foram adquiridas em casa agropecuária da marca Feltrin Sementes, foram colocadas pra germinar em areia. Foi feito o transplantio e concomitantemente foi feita a homogeneização das misturas e o enchimento de sacos de polietileno com capacidade de $1000 \mathrm{ml}$, com os respectivos tratamentos, devidamente identificados e foram dispostos na bancada na casa de vegetação. Em cada saco foram colocadas duas plântulas de mamão e, posteriormente, foi realizado o desbaste após as plântulas terem atingido $5 \mathrm{~cm}$ de altura, deixando apenas uma plântula por recipiente. A irrigação se deu duas vezes ao dia nos horários mais frescos do dia, ou seja, início da manhã e final da tarde com o uso de um regador manual.

As variáveis analisadas foram: número de folhas/planta, diâmetro do coleto $(\mathrm{mm})$ com uso de paquímetro digital da marca Insize, altura da muda $(\mathrm{cm})$ com uso de uma régua graduada em $\mathrm{cm}$ medindo a partir do coleto da muda até a gema apical, matéria fresca e seca da parte aérea e matéria seca e fresca de raiz após 60 dias do transplantio das plântulas. A massa fresca e massa seca foram obtidas em balança analítica, marca Bel, com precisão de quatro casas decimais $(0,0001 \mathrm{~g})$ e posteriormente levada à estufa com circulação de ar forçada, marca Equilam, para secagem à temperatura de $65^{\circ} \mathrm{C}$, por $72 \mathrm{~h}$.

Para os parâmetros da biomassa foi realizado o cálculo do Índice de Qualidade de Dickson (IQD) considerado bom indicador da qualidade de mudas, pois considera no seu cálculo a robustez e o equilíbrio da distribuição da biomassa, sendo ponderados vários parâmetros importantes (Fonseca et al., 2002).

O IQD é determinado em função da altura da parte aérea, do diâmetro do coleto, biomassa seca da parte aérea dada pela soma da biomassa seca do coleto e biomassa seca de folhas e da biomassa seca das raízes, determinado de acordo com a seguinte equação Eq.1 (Dicksonet al., 1960).

\section{Equação 1:}

$$
\mathrm{IQD}=\mathrm{MST} /(\text { Altura/coleto })+(\mathrm{MSPA} / \mathrm{MSR})
$$

Onde: 
IQD - Índice de qualidade de Dickson;

MST - matéria seca total (g);

MSPA - matéria seca parte aérea $(g)$ e

MSR - matéria seca de raiz $(\mathrm{g})$; altura $(\mathrm{cm})$ e coleto $(\mathrm{mm})$.

Os dados foram submetidos à análise de variância e para os dados quantitativos foi empregada a análise de regressão. As análises foram realizadas pelo programa computacional Sistema para Análise de Variância - SISVAR (FERREIRA, 2014).

\section{RESULTADOS E DISCUSSÃO}

Houve diferença significativa $(\mathrm{p}<0,05)$ no efeito das doses do resíduo de piscicultura sobre todas as variáveis avaliadas. Com base nos resultados das análises físico-químicas apresentados na tabela 1, observa-se que os substratos utilizados no T1 e T5 foram os que apresentaram os melhores resultados com relação á sua composição.

Os dados obtidos sobre todas as variáveis avaliadas apresentaram-se significativamente superiores para o $\mathrm{T} 1$, seguido do $\mathrm{T} 5$ conforme observado nos gráficos 1,2 e 3 . Este resultado está relacionado ao fato do substrato comercial Vivatto apresentar características químicas e porosidade desejáveis para um bom substrato, atendendo as necessidades da cultura e apresentando valores expressivos de macro e micronutrientes, bem como o T5 que também apresentou bons rendimentos em virtude de expressar valores nutricionais superiores aos demais tratamentos, com valores de $\mathrm{P}$ e $\mathrm{K}$ relativamente altos e indispensáveis a cultura. Vale ressaltar que o mamoeiro está entre as espécies que requerem maior exigência nutricional por ser uma planta de crescimento, florescimento e frutificação constantes.

Observou-se que o tratamento T1 (substrato Vivatto + CAC) apresentou o maior número médio de folhas $(11,4)$, seguido do T5 (Resíduo de Piscicultura + CAC) com a media de 8,2 folhas por plantas e o T2 (25\% RP+75\%SB+CAC) apresentou o menor índice com 5,4 de média (Gráfico 1). Em um estudo realizado por Silva et. al. (2017) testando doses do resíduo de piscicultura na cultura do maracujá observaram que a diferença no número de folhas se deu principalmente devido as diferentes concentrações de nitrogênio (N) nos substratos, o que de acordo com Oliveira et al. (2004), o N é o 
segundo elemento mais exigido pelo mamão, sendo importante para o crescimento vegetativo da planta não podendo faltar nos primeiros cinco a seis meses após o plantio.

Através das análises químicas dos substratos nota-se que os teores de cálcio $\left(\mathrm{Ca}^{2+}\right)$, e magnésio $\left(\mathrm{Mg}^{2+}\right)$ encontram-se baixos em todos os tratamentos com dosagens do resíduo de piscicultura, já no $\mathrm{T} 1$ os valores de $\mathrm{Ca}^{2+}$ e $\mathrm{Mg}^{2+}$ encontram-se em quantidades desejáveis para a produção de mudas, no entanto, o $\mathrm{pH}$ de todos os tratamentos encontram-se variando de bom a alto, sendo estes valores relevantes para a cultura, como afirma Souza (2000), os valores de $\mathrm{pH}$ mais adequados para a cultura do mamoeiro variam entre 5,5 a 6,7. Embora os teores de $\mathrm{Ca}^{2+}$ de $\mathrm{Mg}^{2+}$ estejam relativamente baixos nos tratamentos que contém as doses do resíduo, os teores de potássio $\left(\mathrm{K}^{+}\right)$, e fósforo $(\mathrm{P})$, encontram-se consideravelmente altos, valores estes que de acordo com Simão (1998), são de grande relevância para a cultura do mamoeiro, principalmente o fósforo que exerce influência na emissão de folhas e no tamanho da planta.

Gráfico 1 - Variação do número de folhas sob diferentes doses de resíduos de piscicultura em mudas de mamão.

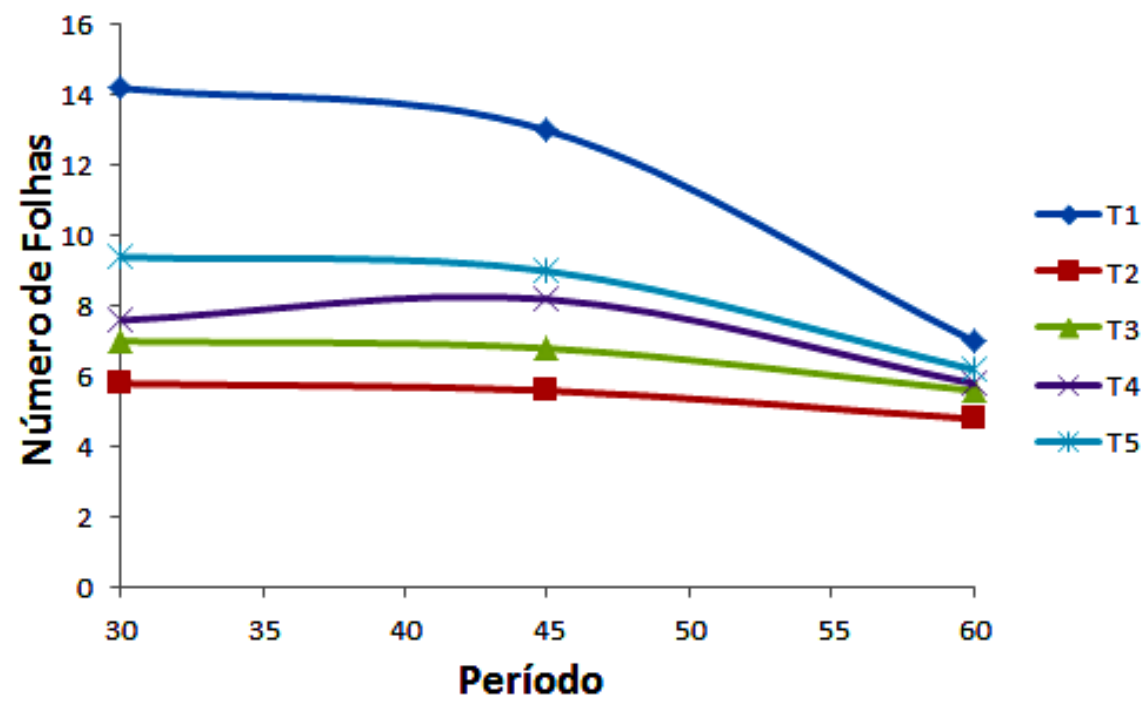

$\begin{array}{lll}30 \text { dias: } 1,4142 x^{2}-9,2657 x+21,04 & R^{2}=78,90 \\ 45 \text { dias: } 1,1857 x^{2}-7,6542 x+18,44 & R^{2}=70,87 \\ 60 \text { dias: } 0,3285 x^{2}-2,0314 x+8,36 & R^{2}=59,33\end{array}$

Com base no gráfico 1, nota-se que houve um declínio abrupto do número de

folhas nos tratamentos a partir dos 45 dias, o T1 se mostrou sempre com melhor desempenho, seguido do T5, enquanto que o T2 apresentou menor número de folhas, 
Miyake et al. (2017), observaram que as plantas de maracujazeiro amarelo obtiveram melhores resultados relacionados ao número de folhas quando estes utilizaram a dosagem máxima de $\mathrm{N}\left(600 \mathrm{mg} \mathrm{dm}^{-3} \mathrm{~N}\right)$ aos substratos, e Weir \&Cresswell (1993) acrescentam que são necessárias adições regulares desse nutriente aos solos, pelo fato de apresentar acentuado dinamismo.

Por se tratar de um nutriente importante para o crescimento vegetativo e de alta mobilidade no solo, a planta do mamoeiro necessita de dosagens constantes de nitrogênio, que provavelmente possa ter se esgotado dos substratos em virtude do consumo pela planta, por lixiviação ou até mesmo por volatilização. Mendonça et al., (2009) fizeram aplicações de doses de N, utilizando a uréia em cobertura e observaram resultados significativos para o número de folhas, dentre outras variáveis para a cultura do mamoeiro, mostrando assim que a adubação nitrogenada em cobertura contribui com o aumento dos índices de qualidade da planta.

$\mathrm{O}$ fato do Tratamento T2 ter apresentado menor número de folhas, se dá também em decorrência deste tratamento ter recebido a menor dosagem de resíduo de piscicultura (RP), já a redução do número de folhas nos demais tratamentos pode ter ocorrido em virtude da adição da casca de arroz carbonizada aos tratamentos.

Por tratar-se de um material altamente lignificado e rico em carbono, a palha de arroz é de elevada relação $\mathrm{C} / \mathrm{N}$, o que faz com que sua decomposição ocorra de forma lenta. A casca de arroz carbonizada é bastante utilizada em substratos por esta condicionar principalmente porosidade e umidade ao composto, sendo interessante dosar a proporção de casca com o solo ou fontes de matéria orgânica para que não haja macroporosidade perdendo desta forma nutriente por lixiviação. (Moreira \& Siqueira, 2006)

É preferível que se utilize a casca de arroz já em estado de decomposição, para que não haja imobilização de nutrientes do substrato. Tendo em vista os resultados apresentados pelos tratamentos, deduz-se que um dos fatores que possa ter interferido no número de folhas foi a adição da CAC ainda imatura nos tratamentos, ou seja, esta não estava suficientemente degradada, ocasionando a imobilização temporária dos nutrientes pela biomassa microbiana na tentativa de decompor este material, comprometendo a disponibilidade de nutrientes para as mudas. 
Gráfico 2 - Variação do diâmetro do coleto das plantas de mamão sob diferentes doses de resíduos de piscicultura em Rorainópolis.

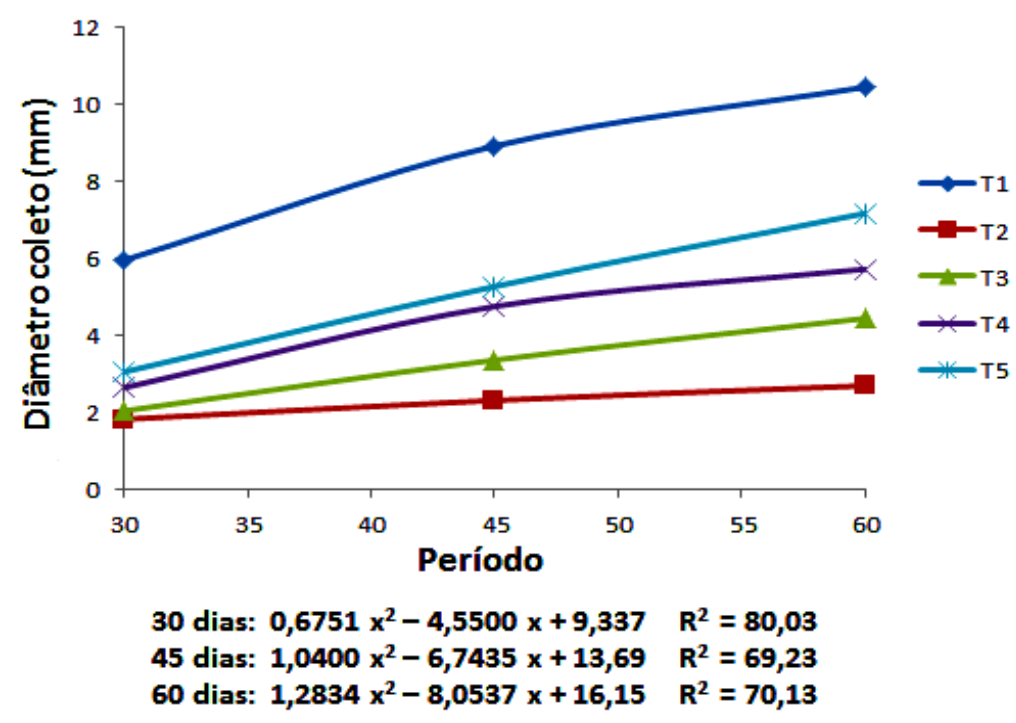

Gráfico 3 - Variação da altura das plantas de mamão sob diferentes doses de resíduos de piscicultura em Rorainópolis.

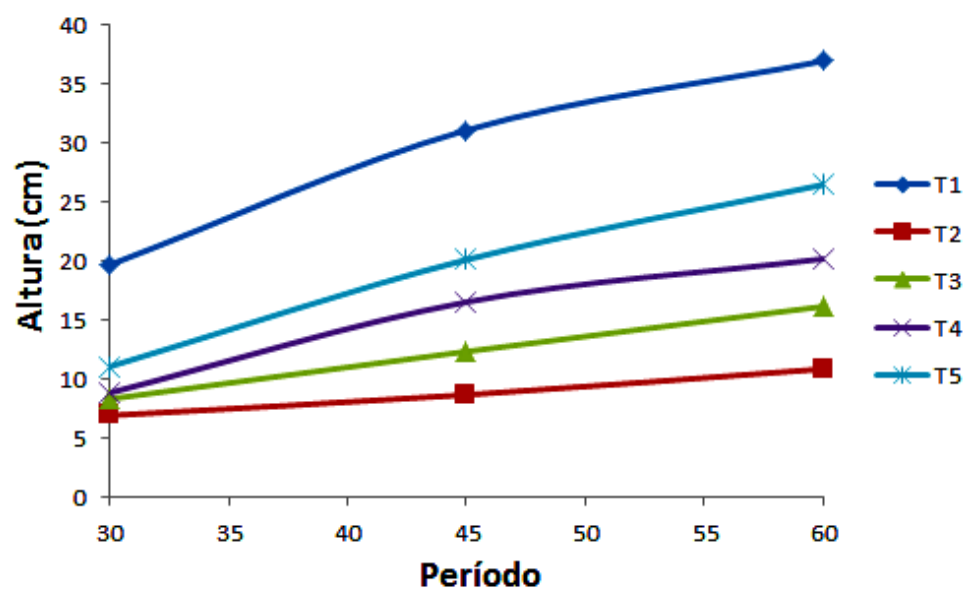

$\begin{array}{ll}30 \text { dias: } 2,0700 x^{2}-13,99 x+30,12 & R^{2}=80,78 \\ 45 \text { dias: } 3,7500 x^{2}-23,92 x+48,27 & R^{2}=73,12 \\ \text { 60 dias: } 4,5300 x^{2}-28,37 x+57,38 & R^{2}=74,41\end{array}$

Os dados de diâmetro do caule das mudas de mamoeiro também foram afetados significativamente pelo incremento das doses do resíduo, conforme equação de regressão (gráfico 2), nota-se que o T5 obteve a maior média de diâmetro $(5,177 \mathrm{~mm})$ quando comparado aos demais substratos que continham as doses do RP, já o T1 obteve a melhor média também para esta variável. Embora o T1 tenha se sobressaído sobre os 
demais tratamentos, Maranaet al., (2008), verificaram que mudas de cafeeiro tiveram melhor desenvolvimento com uso de adubos de liberação lenta que a adubação convencional, tanto para a altura das mudas como para diâmetro do caule.

As mudas de mamoeiro apresentaram resposta positiva à medida que foi incrementado o RP conforme observado no gráfico 3, sendo esta resposta interessante por corroborar com relatos de Nogueira Filho \& Castro (2003), que afirmam que mudas de mamoeiro devem ter entre 15 e $25 \mathrm{~cm}$ de altura para serem levadas a campo. Deste modo observa-se que o $\mathrm{T} 1$ destacou-se entre os demais com altura superior ao necessário, sendo o T2 o único tratamento a não apresentar altura compatível com o desejável para o transplantio em local definitivo. Nota-se que no T5 as plantas se desenvolveram com índice superior aos demais tratamentos que foram adicionados doses do RP, e provavelmente, estas não alcançaram resultados semelhantes ao T1 em virtude da deficiência nutricional do substrato e pela imobilização temporária de nutrientes para a decomposição da CAC, ou pela lixiviação destes.

Os resultados referentes à matéria fresca parte aérea (MFPA), matéria fresca raiz (MFR), matéria seca parte aérea (MSPA), matéria seca raiz (MSR) e índice de qualidade de Dickson (IQD) das mudas de mamão estão apresentados na tabela 3.

Tabela 3 - Matéria fresca parte aérea, matéria fresca raiz, matéria seca parte aérea, matéria seca raiz e índice de qualidade de Dickson de mudas de mamão em Rorainópolis - RR.

\begin{tabular}{cccccc}
\hline Tratamentos & MFPA $(\mathrm{g})$ & MFR $(\mathrm{g})$ & MSPA $(\mathrm{g})$ & MSR $(\mathrm{g})$ & IQD \\
\hline T1 & $34,11 \mathrm{a}$ & $29,80 \mathrm{a}$ & $4,96 \mathrm{a}$ & $2,57 \mathrm{a}$ & $1,34 \mathrm{a}$ \\
T2 & $1,40 \mathrm{~d}$ & $0,77 \mathrm{c}$ & $0,18 \mathrm{c}$ & $0,07 \mathrm{c}$ & $0,04 \mathrm{c}$ \\
T3 & $3,74 \mathrm{~d}$ & $1,96 \mathrm{c}$ & $0,51 \mathrm{c}$ & $0,17 \mathrm{c}$ & $0,10 \mathrm{c}$ \\
T4 & $8,61 \mathrm{c}$ & $7,15 \mathrm{~b}$ & $1,33 \mathrm{~b}$ & $0,73 \mathrm{~b}$ & $0,38 \mathrm{~b}$ \\
T5 & $12,46 \mathrm{~b}$ & $6,21 \mathrm{~b}$ & $1,96 \mathrm{~b}$ & $0,62 \mathrm{~b}$ & $0,38 \mathrm{~b}$ \\
\hline $\mathrm{CV}(\%)$ & 15,48 & 23,52 & 26,50 & 33,46 & 17,27 \\
\hline
\end{tabular}

T1 (substrato comercial + CAC), T2 (25\% Resíduo de Piscicultura+75\% Solo de Barranco + CAC), T3 (50\% Resíduo de Piscicultura+50\% Solo de Barranco + CAC), T4 (75\% Resíduo de Piscicultura + 25\% Solo de Barranco + CAC), e T5 (100\% 
Resíduo de piscicultura $+\mathrm{CAC})$; coeficiente de variação $(\mathrm{CV})$. Médias seguidas pela mesma letra, na coluna, não diferem pelo teste Scott Knott a 5\% de probabilidade.

Os resultados obtidos para massa fresca da parte aérea demonstraram que o tratamento T1 também obteve os melhores rendimentos para esta variável. O T5 demonstrou-se superior quando comparado aos demais que continham RP em sua composição, e o T2 a menor média devido à baixa disponibilidade de nutrientes em função da dosagem utilizada do RP para o T2. Cunha et. al., (2015), observaram que o uso de diferentes doses de fósforo na cultura do maracujá proporcionou incremento da variável massa fresca da parte aérea, sendo a maior dosagem utilizada a que apresentou melhor resultado.

Para a variável massa fresca de raiz, os resultados assemelham-se aos das demais variáveis, sendo o T1 responsável pelo melhor índice, e o T2 o menor. Mendonça (2003), verificou maior massa fresca de raiz de mudas de mamoeiro nos tratamentos que continham esterco bovino, sendo este, fonte de matéria orgânica e nutrientes responsáveis pelo incremento desta variável.

O tratamento T1 apresentou maior média de massa seca da parte aérea $(4,96 \mathrm{~g})$; seguido do T5 com 1,96 g, enquanto o tratamento T2 apresentou a menor produção $(0,18 \mathrm{~g})$, podendo este resultado ser justificado corroborando com Silva et. al. (2017) que utilizando resíduo de piscicultura na produção de mudas de maracujá constataram que a maior produção de massa seca está ligada à disponibilidade de nitrogênio no solo ou no substrato e à capacidade da planta de absorver este nutriente.

Mendonça et al. (2003), observaram que a adubação nitrogenada em cobertura na forma de uréia proporcionou diferenças significativas no aumento da matéria seca das mudas de mamoeiro formosa, uma vez que o nitrogênio contribui para o crescimento vegetativo das plantas, e atua principalmente nas taxas de iniciação e expansão foliar, no tamanho final das folhas e no alongamento do caule (SCHRÖDER et al., 2000). resultados estão relacionados aos distintos teores nutricionais presentes nos tratamentos 
(Tabela 1 e 2). Mendonça et al. (2003), verificaram na cultura do mamoeiro que para a variável matéria seca de raiz a melhor resposta foi observada quando adicionado ao substrato 1,975 mg de N, já Peixoto (1999), observou que o aumento da dose de matéria orgânica ao substrato proporcionou aumento da massa seca de raiz em mudas de maracujá.

$\mathrm{O}$ índice de qualidade de Dickson encontrado no experimento foi superior a 0,2 para os tratamentos T1, T4 e T5, conforme observado na tabela 3 onde o T1 foi o que apresentou maior índice com média de 1,34, e o T4 e T5 um valor de 0,38. De acordo com Silva et al. (2011), mudas com maior IQD são as mais robustas e com melhor distribuição de fitomassa, o que permite grande capacidade de desenvolvimento a campo, por apresentarem alto vigor. Fonseca et al. (2002) estabeleceu que o índice mínimo para o transplantio da muda deve ser de 0,2 indicando capacidade da planta ser levada a campo.

Henz (2016), avaliando o desempenho do biochar produzido com resíduos de serragem na produção de mudas de mamão inoculadas com fungos micorrízicos arbusculares verificou que o índice de qualidade de Dickson encontrado no experimento foi inferior a 0,2 para todos os tratamentos, demonstrando que as mudas não encontravam-se em condições de sobrevivência em campo.

Barros et al. (2017), avaliando mudas de maracujá, observaram que os tratamentos NS, CS, AB25, B25, AB50 e AB75 com biochar ativado e não ativado, apresentaram valores superiores a 0,2 para o IQD, indicando plantas de boa qualidade, com capacidade de se desenvolverem em campo.

As mudas de mamoeiro apresentaram incremento positivo para todas as variáveis, à medida em que se aumentaram as doses de resíduo de piscicultura sendo estas respectivamente, $25 \%, 50 \%, 75 \%$ e $100 \%$, demostrando o efeito benéfico deste composto no crescimento e desenvolvimento das mudas.

As plantas de mamoeiro poderiam elevar seus índices se o substrato apresentasse em sua composição uma mistura de $50 \%$ de RP $+50 \%$ de SC, bem como o uso de adubação nitrogenada de cobertura gradualmente, e como forma de aumentar a porosidade incrementar esterco ou até mesmo a palha de arroz carbonizada, porém em um nível mais elevado de decomposição. 


\section{CONCLUSÃO}

O uso de resíduo de tanque de piscicultura mostrou-se eficiente para a produção de mudas de mamoeiro, sendo as dosagens $75 \%$ e $100 \%$ as que apresentaram melhor desempenho das mudas.

\section{REFERÊNCIAS}

Barros, D.L. de.et al. Biochar of sawdust origin in passion fruit seedling production.JournalofAgriculturalScience.2017.

CHAVES, S. W. P.; SILVA, I. J. O. Integração da Piscicultura com a Agricultura Irrigada. THESIS São Paulo, ano III, v. 6, p. 9-17, $2^{\circ}$ Semestre. 2006. Disponível em: <http://www.cantareira.br/thesis2/ed_6/2_iran.pdf>. Acessado em: 01/07/2018

CUNHA, D.L. et al.Massa fresca e seca da parte aérea e raiz em função da aplicação de super simples em mudas de maracujá. XXXV Congresso Brasileiro de Ciência do Solo. Natal - RN.2015. Disponível em: <http://eventosolos.org.br/cbcs2015/ arearestrit a/arquivos/433.pdf>. Acessado em: 19/07/2018

DICKSON, A.; LEAF, A. L.; HOSNER, J. F. Quality appraisal of whites price and white pine seedling stock in nurseries. For. Chron., v. 36, p. 10-13,1960. Disponível em: <http://www.scielo.br/scielo.php?script=sci_nlinks\&ref=000069\&pid=S1516$0572201100030000500004 \& \operatorname{lng}=$ pt>. Acessadoem: 13/07/2018

FERREIRA, Daniel Furtado. Sisvar: a Guide for its Bootstrap procedures in multiple comparisons.Ciênc. agrotec. [online]. 2014, vol.38, n.2, pp. 109-112. ISSN 1413-7054. Disponível em:<http://dx.doi.org/10.1590/S1413-70542014000200001>. Acessado em: 30/06/2018

FONSECA, E. P. et al. Padrão de Qualidade de mudas de Trema micrantha (L.) Blume., produzidas sob diferentes períodos de sombreamento. Revista Árvore, v. 26, n. $4, \quad$ p. $515 \quad$ - 523, 2002. Disponível em: <http://www.redalyc.org/pdf/488/48826415.pdf>. Acessado em: 13/07/2018 
HENZ, F.L. Avaliação do desempenho do biochar na fase de produção de mudas de mamão inoculados com fungos micorrizicosarbusculares no município de rorainópolis, roraima. UERR. 2016.

HUSSAR, G. J. et al. Aplicação da água de escoamento de tanque de piscicultura na irrigação da alface: aspectos nutricionais. Revista Ecossistema, v.27, n.1,2, p.49-52, jan.-dez.2002. Disponível em: <http://ferramentas.unipinhal.edu.br/ecossistema/viewart icle.php?id=60>. Acessado em: 18/06/2018.

KOEHLER, A. D. Embriogênese somática em mamoeiro (Caricapapaya L.): anatomia, histoquímica e influência de ACC, AVG e STS e de pulsos de 2,4-D. (Dissertação Mestrado).UFV, 2004. Disponível em: <http://www.locus.ufv.br/handle/123456789/8827>. Acessado em: 19/06/2018.

MARANA, J.P. et al. Índices de qualidade e crescimento de mudas de café produzidas em tubetes. Ciência Rural, v.38, n.1, jan-fev, 2008. Disponível em: <http://www.redalyc.org/html/331/33138107/>. Acesso em: 08/08/2018.

MENDONÇA, V. et al. Adubação nitrogenada em cobertura e substratos na produção de mudas de mamoeiro 'formosa'. Ciênc. agrotec., Lavras, v. 33, n. 3, p. 668-675, maio/jun., 2009. Disponível em: <http://www.scielo.br/scielo.php?pid=S141370542009000300002\&script=sci_a bstract\&tlng=es >. Acessado em: 19/08/2018.

MENDONÇA, V.et al.. Diferentes substratos e recipientes na formação de mudas de mamoeiro Sunrise Solo. Revista Brasileira de Fruticultura, Jaboticabal, v. 25, n. 1, p. 127-130, abr. 2003. Disponível em: <http://www.scielo.br/pdf/rbf/v25n1/a36v25n1.pdf/>. Acessado em: 11/07/2018.

MIYAKE, R. T. M. et al. Substrato e adubação nitrogenada na produção de mudas de maracujazeiro amarelo em condições protegidas. ColloquiumAgrariae, v. 13, n.1, Jan-Abr. 2017, p.57-65. Disponível em: $<$ http://revistas.unoeste.br/revistas/ojs/index.php/ca/article/viewArticle/1453>. Acessado em: 15/08/2018. 
MOREIRA, F.M.S. \& SIQUEIRA, J.O. Microbiologia e bioquímica do solo. 2.ed. Lavras: Universidade Federal de Lavras, 2006. 729p. Disponível em: <http://www.esalq.usp.br/departamentos/lso/arquivos_aula/LSO_400\%20Livro\%20$\% 20$ Microbiologia\%20e\%20bioquimica\%20do\%20solo.pdf>. Acessadoem: 25/08/2018.

NOGUEIRA FILHO G.C.; CASTRO A.M. Recomendações técnicas para o cultivo do mamoeiro em Roraima. Boa Vista, Embrapa Roraima. 10p. (Circular Técnica 4). 2003.

OLIVEIRA, A. M. G., et al. Nutrição, calagem e adubação do mamoeiro. In: VITTI, G. C.; MALAVOLTA, E.; BRASIL SOBRINHO, M. O. C.; MARIN, S .L. D. Nutrição e adubação do mamoeiro. Cruz das Almas: Embrapa Mandioca e Fruticultura, 2004. p. 5-9. (Circular Técnica, 69). Disponível em: $<$ https://www.agrolink.com.br/downloads/aduba \%С3\%A7\%C3\%A3o\%20nutri\%C3\%A7\%C3\%A3o\%20e\%20calagem\%20do\%20mam oeiro\%20embrapa.pdf>. Acessadoem: 08/08/2018.

PEIXOTO, J.R. et al.Adubação orgânica e fosfatada no desenvolvimento de mudas de maracujazeiro. Revista Brasileira de Fruticultura, v.21, p.49-51, 1999.

SCHRÖDER, J.J.et al.Does the crop or the soil indicate how to save nitrogen in maize production : Reviewing the state of the art. Field CropsResearch, v.66, p.151$164,2000$.

SEPLAN-Secretaria de Estado do Planejamento e Desenvolvimento de Roraima Informações Socioeconômicas do Município de Rorainópolis - RR 2014, $4^{a}$ edição. Elaboração: DIEP. Boa Vista - RR, 2014. 79 pag. Disponível em: http://www.seplan.rr.gov.br acesso em :16/07/2018.

SILVA, F. O. R.et al. Efeito do resíduo de tanque de piscicultura na produção de mudas de maracujazeiro. Bol. Ind. Anim., Nova Odessa,v.74, n.1, p.58-64, 2017. Disponível em: <http://www.iz.sp.gov.br/pdfsbia/1490884879.pdf>. Acessado em: 19/06/2018. 
SIMÃO, S. Tratado de fruticultura. Piracicaba: FEALQ, 1998. 760p.

SMIDERLE, O.J.; MINAMI,K. Emergência e vigor de plântulas de goiaba em diferentes substratos. Revista Científica Rural, Bagé, v.6,n.1,p.38-45,2001. Disponível em: <http://bdpi.usp.br/item/001222337>. Acessado em: 21/06/2018.

SOUZA, J.S. Aspectos socioeconômicos. In: TRINDADE, A.A. (Coordenador) Brasília. EMBRAPA: Mamão produção: aspectos técnicos. 2000. p.10. Disponível em: <https://livimagens.sct.embrapa.br/amostras/00065690.pdf>. Acessado em: $18 / 06 / 2018$.

WEIR, R. G.; CRESSWELL, G. C. Plant nutriente disorders 3 : vegetable crops. Sydney: [s.n.], 1993. 105 p. 